\title{
INTRODUCTION
}

\section{Jellyfish blooms and ecological interactions}

\author{
Robert H. Condon ${ }^{1, *}$, Cathy H. Lucas ${ }^{2, *}$, Kylie A. Pitt ${ }^{3, *}$, Shin-ichi Uye ${ }^{4, *}$ \\ ${ }^{1}$ Department of Biology and Marine Biology, Center for Marine Science, University of North Carolina Wilmington, \\ 5600 Marvin K. Moss Lane, S College Road, Wilmington, NC 28409, USA \\ ${ }^{2}$ Ocean and Earth Science, National Oceanography Centre, University of Southampton, European Way, \\ Southampton SO14 3ZH, UK \\ ${ }^{3}$ Griffith School of Environment and Australian Rivers Institute, Griffith University, Gold Coast Campus, Queensland 4222, \\ Australia \\ ${ }^{4}$ Graduate School of Biosphere Science, Hiroshima University, Higashi-Hiroshima 739-8528, Japan
}

\begin{abstract}
Scientific and public interest in the biology and ecology of gelatinous zooplankton (jellyfish) has increased significantly over the past two decades. This Theme Section represents the proceedings of the 4th International Jellyfish Blooms Symposium held in Hiroshima, Japan, in June 2013; to date, this was the largest meeting ever of the international jellyfish community. Research highlights presented in this volume include studies on jellyfish blooms at various spatiotemporal scales, jellyfish population dynamics, physiology and ecology, interactions between jellyfish and predators, jellyfish age, growth and diversity, and the fate of jellyfish biomass.
\end{abstract}

KEY WORDS: Jellyfish · Gelatinous zooplankton · Medusae $\cdot$ Ctenophores · Salp · Polyp · Ecology · Biogeochemistry

Resale or republication not permitted without written consent of the publisher

Interest in the biology and ecology of gelatinous zooplankton (hereafter 'jellyfish') has increased over the past two decades, primarily due to the appearance of high numbers of nuisance species and its effects on human activities in some coastal regions. Jellyfish research is in its infancy. Despite increasing global interest in jellyfish, important knowledge gaps exist, and limited funding is a continuing challenge. In addition to local research efforts, international collaboration and multidisciplinary, synthetic approaches are helping to bridge some knowledge gaps, in particular research being conducted in jellyfish blooming areas such as the Mediterranean (e.g. MED-JELLY RISK project) and the East Asian Marginal Seas (e.g. STOP JELLY project), as well as by the Global Jellyfish Group (see Condon et al. 2012).

Over the past 14 years, 4 International Jellyfish Blooms Symposia have been convened to synthesize information, harness collaboration between senior and early career scientists, and highlight research priorities. In 2000, the inaugural symposium was held in Gulf Shores, Alabama, USA with 56 participants from 12 countries, followed by conferences held on the Gold Coast, Queensland, Australia in 2007, and Mar del Plata, Argentina in 2010. These symposia have spawned peer-reviewed, and highly cited, proceedings in international journals (Purcell et al. 2001, 2012, Pitt \& Purcell 2009).

The most recent symposium was held in Hiroshima, Japan, in June 2013, with a record 137 participants from 28 countries. In Asia, serious jellyfish blooms are occurring in association with increased anthropogenic impacts on marine ecosystems (Fig. 1). Hence this first meeting in Asia lured about 50 Asian jellyfish scientists to the conference. Overall, there were 58 oral and 76 poster presentations, with many of the presentations by students and early career researchers. The next symposium will be held in Barcelona, Spain, in 2016.

At the Alabama symposium several research priorities were identified, including the identification of 
environmental drivers and trends in jellyfish blooms, polyp ecology, and determination of the roles of jellyfish in food webs:

(1) Mills (2001) considered whether global jellyfish populations are increasing, but was restricted in her conclusions due to the lack of existing datasets. In the meantime, an open-access jellyfish database has been constructed, the Jellyfish Database Initiative (JeDI), and 3 global analyses have been published (Brotz et al. 2012, Condon et al. 2013, Lucas et al. 2014). The first book dedicated to jellyfish blooms has also been published (Pitt \& Lucas 2014).

(2) Early studies focused on medusae, and virtually nothing was known about the microscopic benthic polyp stage of the life cycle. This knowledge gap has been addressed over the past decade, and continues to be a research priority, with many studies conducted on in situ population dynamics, location and habitat preference, as well as basic functional biology of polyps (e.g. metabolism) and the environmental factors influencing growth and asexual reproduction.

(3) Trophic interactions and fisheries management were highlighted as another research priority. Since then, several studies have been published examining the roles of jellyfish in pelagic food webs, biogeochemical cycles and flux to the deep sea, and effects on fisheries and ecosystem services; this has made it possible to include jellyfish in ecosystem models (Pauly et al. 2009). Molecular tools and other novel technology (e.g. In Situ Ichthyoplankton Imaging System) have enabled us to better identify and describe jellyfish biodiversity worldwide.

The present Theme Section with the Hiroshima symposium proceedings builds on the hard work that

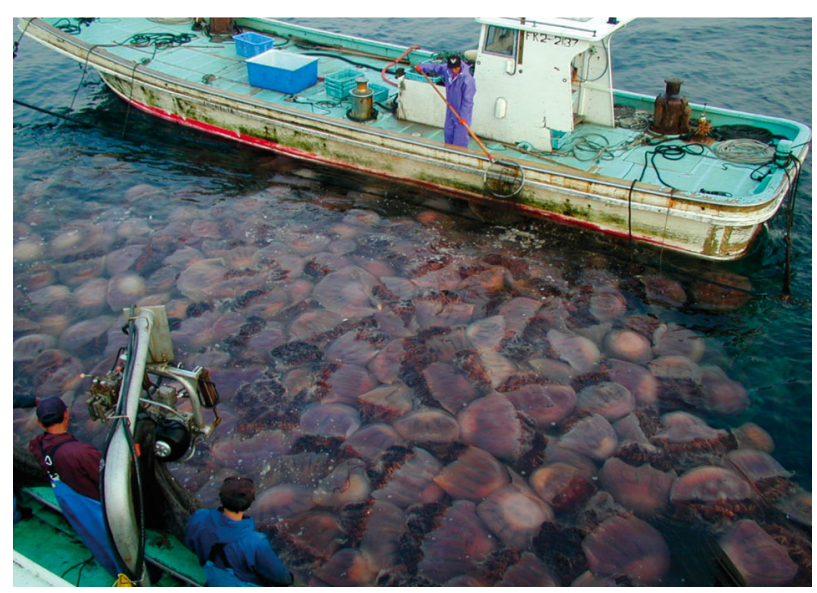

Fig. 1. Nemopilema nomurai medusae off the coast of Japan Photo: Shin-ichi Uye the jellyfish research community has achieved over the past decade in addressing these research priorities. These achievements in jellyfish ecology were highlighted by the 3 plenary speakers at the conference, including a status update of Mills (2001) on the validity of current paradigm of a global increase in jellyfish (Condon et al. 2013), a new understanding of the roles jellyfish play in mediating carbon flows in food webs and export to the deep sea, and the biomechanical constraints on the evolution of jellyfish (Acuña et al. 2011). The studies in this Theme Section advance our understanding on a variety of jellyfish topics: blooms at various spatiotemporal scales, population dynamics, physiology and ecology, interactions between jellyfish and predators, jellyfish age, growth and diversity, and the fate of jellyfish biomass.

We dedicate this Theme Section to our friend and colleague, Hermes Mianzan, who passed away before its completion.

\section{LITERATURE CITED}

Acuña JL, López-Urrutia A, Colin S (2011) Faking giants: The evolution of high prey clearance rates in jellyfishes. Science 333:1627-1629

Brotz L, Cheung WWL, Kleisner K, Pakhomov E, Pauly D (2012) Increasing jellyfish populations: trends in large marine ecosystems. Hydrobiologia 690:3-20

Condon RH, Graham WM, Duarte CM, Pitt KA and others (2012) Questioning the rise of gelatinous zooplankton in the world's oceans. Bioscience 62:160-169

Condon RH, Duarte CM, Pitt KA, Robinson KL and others (2013) Recurrent jellyfish blooms are a consequence of global oscillations. Proc Natl Acad Sci USA 110: 1000-1005

Lucas CH, Jones DOB, Hollyhead CJ, Condon RH and others (2014) Gelatinous zooplankton biomass in the global oceans: geographic variation and environmental drivers. Glob Ecol Biogeogr 23:701-714

Mills CE (2001) Jellyfish blooms: are populations increasing globally in response to changing ocean conditions? Hydrobiologia 451:55-68

Pauly D, Graham W, Libralato S, Morissette L, Deng Palomares ML (2009) Jellyfish in ecosystems, online databases, and ecosystem models. Hydrobiologia 616:67-85

Pitt KA, Lucas CH (2014) Jelllyfish blooms. Springer Science + Business Media, Dordrecht, doi:10.1007/978-94-0077015-7

Pitt KA, Purcell JE (2009) Jellyfish blooms: Causes, consequences and recent advances. Developments in Hydrobiology 206. Springer, Dordrecht. (Reprinted from Hydrobiologia 616)

Purcell JE, Graham WM, Dumont HJ (2001) Jellyfish blooms: ecological and societal importance. Developments in Hydrobiology 155. Kluwer Academic Publishers, Dordrecht. (Reprinted from Hydrobiologia 451)

Purcell JE, Mianzan HW, Frost JR (2012) Jellyfish blooms: interactions with humans and fisheries. Hydrobiologia 690. Springer, Dordrecht 